\title{
RAPD analysis of systematic relationships among the Cervidae
}

\author{
SERGIO COMINCINI $\ddagger_{*}^{*}$, MASSIMO SIRONI§, CLAUDIO BANDI $\$ \S$, CECILIA GIUNTAף, \\ MICHELE RUBINI \& FRANCESCO FONTANA \\ †.D.V.G.A.-C.N.R., via Celoria 10, 20133 Milano, \$Dipartimento di Genetica e Microbiologia, Università di Pavia, via \\ Abbiategrasso 207, 27100 Pavia, §̧/stituto di Patologia Generale Veterinaria, Università di Milano, via Celoria 10, \\ 20133 Milano and $\uparrow$ Dipartimento di Biologia Evolutiva, Università di Ferrara, via Borsari 46, 44100 Ferrara, Italy
}

\begin{abstract}
We investigated the possible application of RAPD (Random Amplified Polymorphic DNA) analysis to the study of the systematic relationships of five cervid taxa. Amplifications with eight different primers gave reproducible electrophoretic patterns which could be regarded as a data-set consisting of monomorphic and polymorphic characters. Some of these characters are species- and subspecies-specific. Band-sharing analysis and numerical taxonomy methods allowed us to generate a phenetic tree. Our results point out new possible systematic considerations within the examined taxa.
\end{abstract}

Keywords: Cervidae, deer, molecular systematics, RAPD.

\section{Introduction}

Despite the continuous accumulation of palaeontological, morphological and behavioural data, systematic and phylogenetic relationships among the most important Cervidae subfamilies are not yet completely understood (Harrington, 1985; Groves \& Grubb, 1987). Recently several models of phylogenetic relationships, based on different criteria, have been reported. These criteria include: (i) karyotypic analysis (Neitzel, 1987; Wang \& Du, 1988; Fontana \& Rubini, 1990); (ii) studies on constitutive heterochromatin localization (Wessman \& Gripenberger, 1993); (iii) Southern blot hybridization of repetitive DNA (Scherthan et al., 1987); (iv) the distribution of repetitive sequences of IA satellite DNA (Bogenberger et al., 1987); (v) comparative studies of mitochondrial DNA sequences (Miyamoto et al., 1990) and mitochondrial DNA restriction site maps (Cronin, 1991); and (vi) allozyme studies (Emerson \& Tate, 1993).

A molecular technique based on the polymerase chain reaction (PCR) provides an effective tool for the rapid identification of genetic markers known as Random Amplified Polymorphic DNA (RAPD) (Williams et al., 1990; Welsh \& McClelland, 1990). Such markers, derived from priming sites randomly distributed throughout the genome, are inherited in a Mendelian fashion (Rothuizen \& Van Wolferen,

*Correspondence.
1994). These polymorphisms allow the analysis of complex genomes, like those of eukaryotes, without prior knowledge of DNA sequence (Hadrys et al., 1992). The potential use of RAPD in phylogenetic studies (Chalmers et al., 1992; Demeke et al., 1992; Castiglione et al., 1993; Fani et al., 1993; Tibayrenc et al., 1993; Gwakisa et al., 1994; Kaukas et al., 1994; Bandi et al., 1995) and population genetics (Lynch \& Milligan, 1994; Baruffi et al., 1995) has been widely documented in a large variety of organisms. The goal of this work is to study the systematic relationships among the Cervidae by means of RAPD analysis.

\section{Materials and methods}

\section{Specimens and sources of genomic DNA}

The study has been conducted on different species of the Cervidae family: Cervus elaphus (red deer) and Dama dama (fallow deer), from the Cervinae subfamily; Capreolus capreolus (roe deer) and Odocoileus hemious hemious (mule deer) from the Odocoleinae; Muntjac muntjac vaginalis (Indian muntjac) from the Muntjacinae. One bovid species, Bos taurus (Bovidae), was employed as an outgroup. Whole blood samples were obtained from the following species and locations: $C$. elaphus and $D$. dama from Bosco della Mesola (Ferrara, Italy), $C$. capreolus from Bosco di Carrega (Parma, Italy). DNAs of $M . m$. vaginalis and $O . h$. hemious were 
extracted from ATCC (American Type Culture Collection) cell lines (one sample for each species). Bovine DNA was derived from a representative of Italian Fresian breed. DNAs of the other species were extracted by the standard phenol-chloroform procedure from peripherical blood leucocytes (four samples each for $C$. elaphus, D. dama and $C$. capreolus).

\section{Amplification conditions}

Amplification reactions were performed in volumes of $10 \mu \mathrm{L}$ containing $10 \mathrm{~mm}$ Tris- $\mathrm{HCl}$ (pH 8.3), $50 \mathrm{~mm} \mathrm{KCl}, 5 \mathrm{~mm} \mathrm{MgCl}_{2}, 0.01$ per cent gelatin (w/v), 0.1 per cent Triton X-100, $0.2 \mathrm{~mm}$ of each of the dNTPs, $250 \mathrm{ng}$ of each single primer, $10 \mathrm{ng}$ of purified DNA and 0.5 units of Taq DNA polymerase (Promega, USA). The reactions were overlaid with one drop of mineral oil. We report results obtained with the MJ PT-100 Thermal Cycler (Watertown, USA) programmed with a first denaturation of $1 \mathrm{~min}$ and $30 \mathrm{~s}$ at $94^{\circ} \mathrm{C}$, followed by 45 cycles of $30 \mathrm{~s}$ at $94^{\circ} \mathrm{C}, 1 \mathrm{~min}$ at $45^{\circ} \mathrm{C}$ and $2 \mathrm{~min}$ at $75^{\circ} \mathrm{C}$. Two final steps of $10 \mathrm{~min}$ at $75^{\circ} \mathrm{C}$ and $10 \mathrm{~min}$ at $60^{\circ} \mathrm{C}$ were made to extend further the amplification products.

\section{Selection of the primers}

Purified primers were supplied by Genenco (Firenze, Italy) and analysed to determine their annealing temperatures and possible secondary structure formation (oligo 4.0, Medprobe). We used primers ranging in size from 19 to 26 bases, with different nucleotide-proportion $(\mathrm{G}+\mathrm{C}$ content) and designed for other purposes. From a previous screening of a wide set of primer-template combinations, we chose eight primers that gave a high number of polymorphic markers and a high statistically significant percentage of comigrating bands, assumed to be monomorphic characters. Sequences of the selected primers and their $\mathrm{G}+\mathrm{C}$ content (in percentage) are as follows:

\section{P1: 5'-CGAAACAAGCGTGCATGAGCCCGAA}

\section{P2: 5'-CTAATGCAGGAGTCGCATAAGGGAGA}

P3: 5'-GATGAACTCCAGGATAAAATC

P4: 5'-CTTCAGTGACAAAATAGCCAAA

P5: 5'-CCTGACCAGGCACTGGCAGA

P6: 5'-CTCAATAACTTCTGGAGAAAG
P7: 5'-GAAGCAGCCCGGTAGTAGGTTGAGG

P8: 5'-TTTGATGTCTCCTTAGAGT

\section{RAPD detection}

Five $\mu \mathrm{L}$ of each amplification reaction were loaded onto 3 per cent $(\mathrm{w} / \mathrm{v})$ agarose gels $(1.5$ per cent NuSieve-GTG; 1.5 per cent SeaKem-GTG) with TBE buffer $(0.89 \mathrm{M}$ Tris- $\mathrm{OH}, 0.89 \mathrm{M}$ boric acid and $0.11 \mathrm{M} \quad$ EDTA) containing $0.5 \mu \mathrm{g} \mathrm{mL}^{-1} \quad(\mathrm{w} / \mathrm{v})$ ethidium bromide (Sambrook et al., 1989) and electrophoresed at $10 \mathrm{~V} \mathrm{~cm}^{-1}$. Because of the complexity of the patterns, detection of RAPDs was performed using a computer-assisted imaging system (BIOPROFIL-2D, Vilber-Lourmat).

\section{Statistical analysis}

RAPD markers were scored as present or absent and coded as two state characters to calculate a matrix based on the Dice similarity index (Sneath \& Sokal, 1973). Similarity measure computations, principal coordinate (PCO) and cluster analysis (according to the unweighted pair-group method with arithmetic averages, UPGMA) were effected using NTSYs (Exeter Software). Data resampling and matrix calculations for bootstrap analysis were performed using a specifically developed software (available on request). The consensus tree construction was performed using PHYLIP 3.5c (Felsenstein, 1993). The statistical analysis was performed for each primer separately and for the combined data of all the primers.

\section{Results}

The amplifications were carried out twice independently in two different laboratories, using the same thermal cycler model, obtaining reproducible results. The electrophoretic patterns from amplifications with eight different primers (P1-P8) were generally complex: 5-10 monomorphic bands common to all samples and many polymorphic markers, ranging from 50 to $2000 \mathrm{bp}$ in size. The primers gave different species-specific markers in terms of length and intensity of the amplification fragments (Figs 1 and 2 show, as exmples, RAPDs obtained with primers P1 and P2). In addition, all the individuals tested within each group showed a different pattern. The matrix of the estimated values of similarity, including the amplification data, is reported (Table 1). The derived phenetic tree (Fig. 3) clearly

(c) The Genetical Society of Great Britain, Heredity, 76, 215-221. 
discriminates the systematic groups, giving different values of similarity between and within taxa. In particular, the dendrogram shows three main hypothetical taxonomic units (HTU): two HTUs including C. elaphus and D. dama are grouped together in

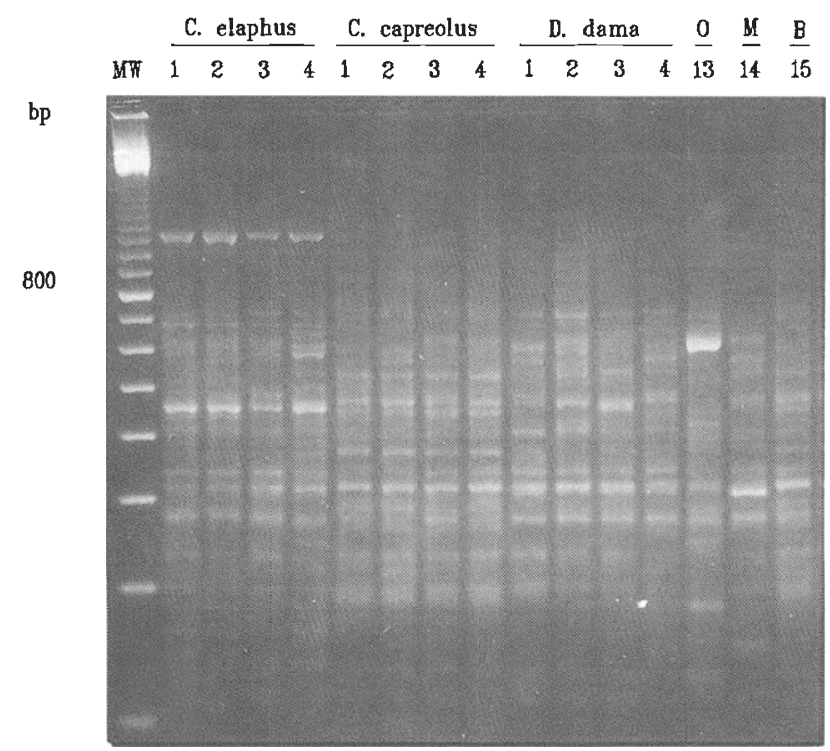

Fig. 1 RAPD patterns obtained with primer P1. The marker (MW) is 100-bp ladder (Pharmacia, Wisconsin). Lanes $13(\mathrm{O}), 14(\mathrm{M})$ and $15(\mathrm{~B})$ are, respectively, Odocoileus hemious hemious, Muntjac muntjac vaginalis and Bos taurus. a single cluster. The third contains the $C$. capreolus. The remaining terminal nodes are the $O$. $h$. hemious and $M . m$. vaginalis. As expected from an outgroup, $B$. taurus stems at the deepest position of the tree. The dendrogram calculated on eight primers is similar to those obtained analysing each single primer (data not shown). The topology of the dendrogram is congruent with the distribution of the groups revealed by the PCO (Fig. 4).

\section{Discussion}

We have applied the RAPD analysis to the study of the systematic relationships in the deer family. This technique is rapid and useful to detect large amounts of polymorphism. Considerable advantages of the technique are that no prior knowledge of the molecular biology of the investigated organisms is required and it is very cost-effective. Theoretically, the number of DNA polymorphisms that can be detected with RAPD analysis is higher than with traditional methods. RAPD data have been computed using the model of fingerprinting analysis, making the assumption that RAPD markers are in Hardy-Weinberg equilibrium within and between loci (Gilbert et al., 1990; Lynch, 1990). This assumption obeys the criteria proposed by Clark \& Lanigan (1993) for estimating population genetic parameters using RAPD data. From a technical point of view, a

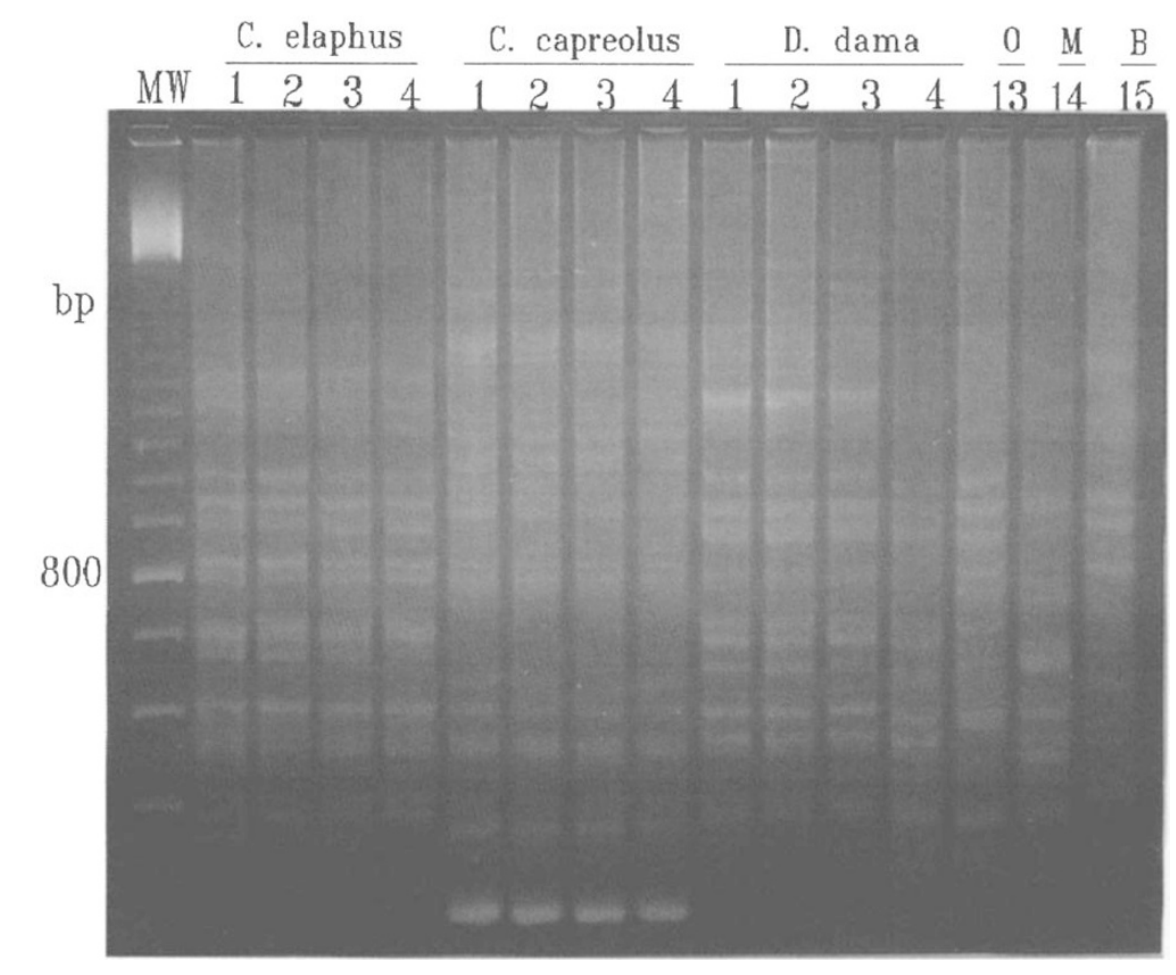

Fig. 2 RAPD patterns obtained with primer P2. The marker (MW) is 100-bp ladder. Lanes $13(\mathrm{O}), 14(\mathrm{M})$ and 15 (B) are, respectively, Odocoileus hemious hemious, Muntjac muntjac vaginalis and Bos taurus. 
Table 1 Matrix of the estimated values of Dice similarity index computated through amplifications with eight primers. C (numbered from 1 to 4) are Cervus elaphus; Cp (1-4) Capreolus capreolus; D (1-4) Dama dama. O, M, B represent, respectively, Odocoileus hemious hemious, Muntjac muntjac vaginalis and Bos taurus

\begin{tabular}{|c|c|c|c|c|c|c|c|c|c|c|c|c|c|c|c|}
\hline & $\mathrm{C} 1$ & $\mathrm{C} 2$ & C3 & $\mathrm{C} 4$ & Cp1 & $\mathrm{Cp} 2$ & Cp3 & Cp4 & D1 & D2 & D3 & D4 & $\mathrm{O}$ & $\mathrm{M}$ & B \\
\hline $\mathrm{C} 1$ & 1.000 & & & & & & & & & & & & & & \\
\hline $\mathrm{C} 2$ & 0.969 & 1.000 & & & & & & & & & & & & & \\
\hline C3 & 0.961 & 0.976 & 1.000 & & & & & & & & & & & & \\
\hline $\mathrm{C} 4$ & 0.947 & 0.961 & 0.954 & 1.000 & & & & & & & & & & & \\
\hline Cp1 & 0.492 & 0.500 & 0.496 & 0.519 & 1.000 & & & & & & & & & & \\
\hline Cp2 & 0.492 & 0.500 & 0.496 & 0.519 & 0.985 & 1.000 & & & & & & & & & \\
\hline Cp3 & 0.496 & 0.504 & 0.500 & 0.523 & 0.977 & 0.977 & 1.000 & & & & & & & & \\
\hline Cp4 & 0.481 & 0.488 & 0.485 & 0.507 & 0.977 & 0.962 & 0.955 & 1.000 & & & & & & & \\
\hline D1 & 0.476 & 0.484 & 0.480 & 0.472 & 0.413 & 0.413 & 0.416 & 0.403 & 1.000 & & & & & & \\
\hline D2 & 0.500 & 0.508 & 0.504 & 0.496 & 0.438 & 0.438 & 0.441 & 0.428 & 0.968 & 1.000 & & & & & \\
\hline D3 & 0.508 & 0.516 & 0.512 & 0.504 & 0.431 & 0.431 & 0.450 & 0.421 & 0.921 & 0.953 & 1.000 & & & & \\
\hline D4 & 0.532 & 0.541 & 0.537 & 0.544 & 0.484 & 0.484 & 0.488 & 0.472 & 0.833 & 0.846 & 0.855 & 1.000 & & & \\
\hline $\mathrm{O}$ & 0.432 & 0.440 & 0.436 & 0.446 & 0.432 & 0.432 & 0.436 & 0.421 & 0.467 & 0.495 & 0.486 & 0.476 & 1.000 & & \\
\hline M & 0.382 & 0.389 & 0.386 & 0.379 & 0.365 & 0.365 & 0.368 & 0.359 & 0.414 & 0.407 & 0.400 & 0.422 & 0.375 & 1.000 & \\
\hline B & 0.330 & 0.336 & 0.333 & 0.345 & 0.348 & 0.348 & 0.351 & 0.356 & 0.234 & 0.248 & 0.226 & 0.239 & 0.250 & 0.220 & 1.000 \\
\hline
\end{tabular}

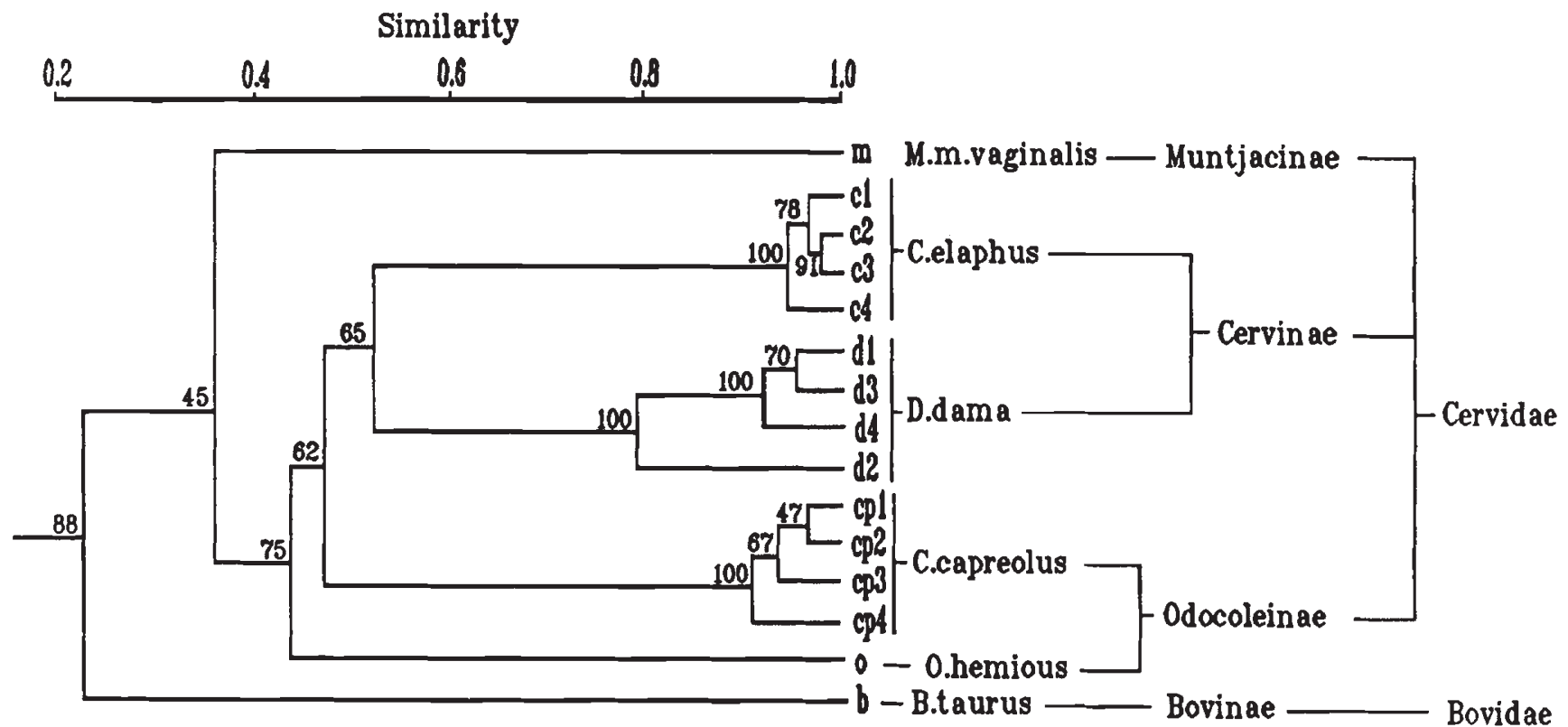

Fig. 3 UPGMA dendrogram based on Dice similarity index calculated from data of all primers (left). On the right is reported the taxonomy of the investigated organisms (species, subfamily and family names). The numbers at the nodes are the bootstrap confidence values obtained after 100 replicates.

high magnesium chloride concentration $(5 \mathrm{~mm})$ combined with a low annealing temperature $\left(45^{\circ} \mathrm{C}\right)$ were selected to enhance the stability of primer/ template interactions, resulting in reproducible fingerprinting-like patterns. According to our experience the protocol does not appear to be strongly dependent on the quality/quantity of target DNA: this fact makes it extremely flexible, applicable without modification to a large variety of organisms, using both purified DNAs and crude extractions (Fani et al., 1994; Bandi et al., 1995; Baruffi et al., 1995). Preliminary primers selection is critical to evaluate those that produce a high statistically significant ratio of mono/polymorphic characters, thus 
Fig. 4 Principal coordinate analysis of the RAPD data obtained with eight primers. The main components $(x, y, z)$ explain 82 per cent of the variance $(56+14+12$ per cent). C (from 1 to 4$)$ are Cervus elaphus; $\mathrm{Cp}$ (1-4) Capreolus capreolus; D (1-4) Dama dama. O, M, $\mathrm{B}$ represent, respectively, Odocoileus hemious hemious, Muntjac muntjac vaginalis and Bos taurus.

providing an internal control of the reliability of the entire process of amplification. each electrophoretic pattern is primer-specific. Additional polymorphisms can be detected with endonuclease digestions of the amplification products (data not shown).

The method has been demonstrated to be valid, being able to distinguish correctly the different species, even within the same subfamily (Cervinae). The similarity between $C$. elaphus and $D$. dama revealed by our results is in total agreement with the data derived from morphological analysis, palaeontological (Groves \& Grubb, 1987), molecular (Scherthan et al., 1987) and karyological (Rubini et al.,
$1990)$ studies. On the contrary, $C$. capreolus and $O$. $h$. hemious, although belonging to the same subfamily, show a low degree of similarity. As a whole, our data suggest a separation of $C$. capreolus from both the Cervinae and the Odocoleinae. This separation has previously been pointed out first by Brooke (1878) and more recently by Groves \& Grubb (1990). Our data are in agreement with these authors who consider these species as belonging to distinct tribes: respectively, Capreolini and Odocoleini. The result that most disagrees with the earlier classification methods, based on anatomical features, is the systematic position of $M . m$. vaginalis. This 
species is considered to be closer to Cervinae because it belongs to Plesiometacarpalia rather than to the more primitive Telometacarpalia, which include all Odocoileinae (Brooke, 1878). A similar conclusion has also been derived from molecular data (Bogengerger et al., 1987; Scherthan et al., 1987; Miyamoto et al., 1990). However, cytogenetic data show that the $M$. m. vaginalis karyotype is extremely different from that of the other species (Wurster \& Benirschke, 1970); this could indicate a long independent evolutionary history for $M . m$. vaginalis. Because for this species and for the $O . h$. hemious, only one cell line sample was available, no genetic variation within the species was observed.

In conclusion, RAPD analysis provides an efficient and sensitive method to estimate the status of organisms of controversial systematics. Further extension of the analysis could better define the phylogenetic relationships among the Cervidae.

\section{Acknowledgements}

We thank V. Sgaramella, G. Damiani and L. Ferretti for helpful suggestions on an earlier draft of this manuscript. The authors are particularly grateful to $M$. Grandini for writing the software for bootstrap analysis. M.S. is supported by a grant from the Fondazione Adriano Buzzati Traverso.

\section{References}

BANDI, C., LA ROSA, G., BARDIN, M. G., DAMIAN , G., COMINCIN], S., TRASCIOTTI, L. AND POZIO, E. 1995. Random amplified polymorphic DNA fingerprinting of eight taxa of Trichinella and their comparison with allozyme analysis. Parasitology, 110, 401-407.

BARUfFl, L., DAMIANI, G., GUGlielmino, C. R., BANDI, C., MALACRIDA, A. R. AND GASPERI, G. 1995. Polymorphism within and between populations of Ceratitis capitata: comparison between RAPD and multilocus enzyme electrophoresis data. Heredity, 74, 425-437.

BOGENBERGER, J. M., NEITZEL, H. AND FITTLER, F. 1987. A highly repetitive DNA component common to all Cervidae: its organisation and chromosomal distribution during evolution. Chromosoma, 95, 154-161.

BroOKE, v. 1878. On the classification of the Cervidae, with a synopsis of the existing species. Proc. Zool. Soc. London, 1878, 883-928.

CASTIGLIONE, S., WANG, G., DAMIANI, G., BANDI, C., BISOFF], S. AND SALA, F. 1993. RAPD fingerprinting identification for taxonomic studies of elite popular (Populus spp.) clones. Theor. Appl. Genet., 87, 54-59.

CHALMERS, K. J., WAUGH, K., SPRENT, J. 1., SIMONS, A. J. AND POWELL, w. 1992. Detection of genetic variation between and within populations of Gliricidia sepium and G. maculata using RAPD markers. Heredity, 69, 465-472.

Clark, A. G. AND Lanigan, C. M. s. 1993. Prospects for estimating nucleotide divergence with RAPDs. Mol. Biol. Evol., 10, 1096-1111.

CRONIN, M. A. 1991. Mitochondrial-DNA phylogeny of deer (Cervidae). J. Mammal., 72, 553-556.

Demeke, T., ADAMS, R. P. AND ChiBbar, R. 1992. Potential taxonomic use of Random Amplified Polymorphic DNA (RAPD): a case study in Brassica. Theor. Appl. Gen., 84, 990-994.

EMERSON, B. C. AND TATE, M. L. 1993. Genetic analysis of evolutionary relationships among deer (Subfamily Cervinae). J. Hered., 84, 226-273.

FANI, R., BANDI, C., BARDIN, M. G., COMINCIN], S., DAMIANI, G., GRIFONI, A. AND BAZZICALUPO, M. 1993. RAPD fingerprinting is useful for identification of Azospirillum strains. Microb. Release, 1, 217-221.

FELSTENSTEIN, J. 1993. PHYLIP (Phylogeny Inference Package) Version 3.5c. Software package distributed by the author. Department of Genetics, University of Washington, Seattle, WA, USA.

FONTANA, F. AND RUBINI, M. 1990. Chromosomal evolution in Cervidae. Biosystems, 24, 157-174.

GILBERT, D. A., LEHMAN, N., O'BRIEN, S. J. AND WAYNE, R. K. 1990. Genetic fingerprinting reflects population differentiation in the California Channel Island fox. Nature, 344, 764-767.

GROVES, C. P. AND GRUBB, P. 1987. Relationships of living deer. In: Wemmet, C. M. (ed.) Biology and Management of the Cervidae, pp. 21-59. Smithsonian Institution Press, Washington, D.C.

GWAKISA, P. S., KEMP, S. J. AND TEALE, T. 1994. Characterisation of Zebu cattle breeds in Tanzania using random amplified polymorphic DNA markers. Anim. Genet., 25, 89-94.

HADRYS, H., BALICK, M. AND SChIERWATER, B. 1992. Applications of Random Amplified Polymorphic DNA (RAPD) in molecular ecology. Mol. Ecol., 1, 55-63.

HARRINGTON, R. 1985. Evolution and distribution of the Cervidae. In: Fennessy, F. F. and Drew, K. R. (eds) The Biology of Deer Production, vol. 22, pp. 3-11. Royal Society New Zealand Bulletin.

KAUKAS, A., DIAS-NETO, E., SIMPSON, A. J., SOUTHGATE, V. R. AND ROLLINSON, V. 1994. A phylogenetic analysis of Schistosoma haematobium group species based on randomly amplified polymorphic DNA. Int. J. Parasitol., 24, 285-299.

LYNCH, M. 1990. The similarity index and DNA fingerprinting. Mol. Biol. Evol., 7, 478-484.

LYNCH, M. AND MILligAN, R. 1994. Analysis of population genetic structure with RAPD markers. Mol. Ecol., 3, 91-99.

MIYAMOTO, M. M., KRAUS, F. AND RYDER, O. A. 1990. Phylogeny and evolution of antlered deer determined from mitochondrial DNA sequences. Proc. Natl. Acad. USA, 87, 6127-6131. 
NEITZEL, H. 1987. Chromosome evolution in Cervidae: karyotypic and molecular aspects. In: Obe, R. and Basler, T. (eds) Cytogenetics, pp. 90-112. Springer, Berlin.

ROTHUIZEN, J. AND VAN WOLFEREN, R 1994. Randomly amplified DNA polymorphisms in dogs are reproducible and display Mendelian transmission. Anim. Genet., 25, 13-18.

RUBINI, M., NEGRI, E. AND FONTANA, F. 1990. Standard karyotype and chromosomal evolution of the fallow deer (Dama dama L.). Cytobios, 155, 155-161.

SAMBROOK, J., FRITSCH, E. F. AND MANIATIS, T. 1989. Molecular Cloning: a Laboratory Manual. Cold Spring Harbor Laboratory Press, New York.

SCHERTHAN, H., ARNASON, U. AND LIMA-DE-FARIA, A. 1987. The chromosome field theory tested in muntjac species by DNA cloning and hybridization. Hereditas, 107, 175-184.

SNEATH, P. H. A. AND SOKAL, H. R. 1973. Numerical Taxonomy. W.H. Freeman, San Francisco.

TIBAYRENC, M., NEUBAUER, K., BARNABÉ, C., GUERRINI, F.,
SKARECKY, D. AND AYALA, F. J. 1993. Genetic characterization of six parasitic protozoa: Parity between random-primer DNA typing and multilocus enzyme electrophoresis. Proc. Natl. Acad. Sci. USA, 90, 1335-1339.

WANG, z. AND DU, R. 1988. Karyotypes and Chromosomal Evolution in Deer. Scientific Publishing House, Beijing.

WELSH, J. AND McCLELLAND, M. 1990. Fingerprinting genomes using PCR with arbitrary primers. $\mathrm{Nucl}$. Acids Res., 18, 7213-7218.

WESSMANN, M. AND GRIPENBERGER, U. 1993. Restriction endonuclease staining profiles in the C-heterochromatin of Cervidae. I. The autosome. Hereditas, 118, 243-249.

WILLIAMS, J. G. K., KUBELIK, A. R., LIVAK, K. J., RAFALKI, J. A. AND TINGEY, S. V. 1990. DNA polymorphisms amplified by arbitrary primers are useful as genetic markers. Nucl. Acids Res., 18, 6531-6535.

WURSTER, D. H. AND BENIRSCHKE, K. 1970. Indian muntjac, Muntiacus muntjac: a deer with a low diploid chromosome number. Science, 168, 1364-1366. 